\title{
ANALISANDO EFEITOS DA POLÍTICA AUTODECLARATÓRIA DO CADASTRO AMBIENTAL RURAL: SOBREPOSIÇÕES E GRILAGEM EM TERRAS PÚBLICAS
}

\author{
ANALYZING THE EFFECTS OF THE SELF-DECLARATORY POLICY OF THE RURAL EN- \\ VIRONMENTAL REGISTRY: OVERLAPS AND GRILAGEM IN PUBLIC LANDS
}

\begin{abstract}
Resumo
O presente trabalho tem como objetivo demonstrar efeitos da política pública do Cadastro Ambiental Rural (CAR) através das noções de efeito-instrumento de James Ferguson e de legibilidade e simplificação do território de James Scott, buscando na antropologia das políticas públicas um aporte capaz de compreender o que efetivamente ocorre nos territórios quando determinada tecnologia de poder é acionada. Será feita uma historicização das legislações ambientais e fundiárias brasileiras, visualizando que mesmo sob diversos dispositivos ainda possuímos grande insegurança jurídica que os novos dispositivos devem tentar suprir. Assim, será apresentado o CAR, seu regramento do Novo Código Florestal Brasileiro, algumas características da política de mapeamento e cadastro dos "posseiros/proprietários rurais" e a implantação da política pública de regularização ambiental. Para analisar esses dados, será utilizada literatura sobre efeitos de política pública e da antropologia das políticas públicas, tentando demonstrar que a política autodeclaratória do CAR produz efeitos através das sobreposições de cadastros em terras públicas, favorecendo grilagem de terras. Por fim, o método utilizado conta-

1 Doutorando de Ciências Sociais em Desenvolvimento, Agricultura e Sociedade (CPDA/UFRRJ), mestre em Desenvolvimento Rural (PGDR/UFRGS) e bacharel em Direito (FURG). Pesquisador do Grupo de Pesquisa Dinâmicas políticas, Estado e Movimentos Sociais (DIPEM-FURG) e Assistente de pesquisa do Observatório de Políticas Públicas para Agricultura (OPPA/CPDA). Orcid: 0000-0002-6877-8615. Email: matheus.korting@gmail.com.
\end{abstract}


rá com análise quali-quantitativa de dados dos resultados da política, como o Boletim Informativo do CAR, realização de um mapa através dos shapefiles apresentados no sistema do CAR e dados secundários obtidos de atores que participam ativamente das questões ambientais e fundiárias brasileiras.

Palavras-chave: Mapeamento. Regularização ambiental. Política pública. Efeitos. Cadastro Ambiental Rural.

\begin{abstract}
This study shows the effects of the public policy of the Environmental Rural Registry (CAR) through the James Ferguson's notion of instrument effect and James Scott's notion of legibility and simplification of territory, seeking in the anthropology of public policies a capable contribution to understand what actually happens in the territories when a specific technology power is activated. A historicization of Brazilian environmental and land laws will be made, showing that even under different provisions we still have great legal uncertainty that the new provisions must try to supply. Thus, the CAR, the regulation of the New Brazilian Forest Code, some characteristics of the mapping and registration policy of the "squatters/ rural landowners", and the implementation of the public policy of environmental regularization are presented. To analyze these data, literature on the effects of public policy and the anthropology of public policies were used, showing that CAR's self-declared policy produces effects by overlapping of registers in public lands, favoring land grabbing. Lastly, the method used includes qualiquantitative analysis based on policy results such as the CAR Newsletter, resulting in a map with shapefiles presented in the CAR system, and secondary data obtained from actors who actively participate in Brazilian environmental and land issues.
\end{abstract}

Keywords: Mapping. Environmental regularization. Public policy. Effects. Environmental Rural Register.

\title{
INTRODUÇÃO
}

O presente trabalho apresentará o Cadastro Ambiental Rural (CAR) a partir do instrumento de cadastramento e mapeamento de todas as propriedades e posses rurais brasileiras enquanto uma política pública ambiental. $O$ CAR é registro público eletrônico de âmbito nacional, obrigatório para todos os imóveis rurais que integra as informações ambientais das propriedades e posses rurais numa base de dados com fins de monitoramento, planejamento ambiental e econômico e combate ao desmatamento, conforme o artigo 29 da Lei 12.651/2012.

Como metodologia de trabalho, foram realizadas consultas em dados secundários do IBGE (Instituto Brasileiro de Geografia e Estatística), de Prefeituras, de Secretarias de meio ambiente, reportagens e consultas públicas do 
Sistema do Cadastro Ambiental Rural. Assim se realizou uma análise quali-quantitativa de dados dos resultados da política como o Boletim Informativo do CAR e se produziu um mapa através dos shapefiles apresentados no sistema do CAR. Também se consultou artigos científicos a respeito de temáticas próximas à grilagem de terras, de pecuária e de desmatamento no território sudeste paraense e realizou entrevistas semiestruturadas com técnicos ambientais das Secretárias de Meio Ambiente de Canaã dos Carajás e Marabá, empresários do ramo da tecnologia, pecuaristas, assentados rurais e representantes de movimentos sociais.

A partir das noções de "efeito-instrumento", de James Ferguson (1980), "legibilidade e simplificação do território", de James Scott (1998) e "biopolítica", de Michel Foucault (2008), em uma abordagem antropológica das políticas públicas o trabalho tem como central o CAR enquanto dispositivo de poder a governar a política ambiental e, mais que isso, por seu caráter autodeclaratório parece transformar as relações de controle, tendo efeitos inclusive nas estruturas fundiárias do país.

O mundo rural para o trabalho, para além de espaço de produção agrária e reprodução socioeconômica, revela-se enquanto território a ser inscrito em polígonos pelos próprios cadastrantes do CAR em todo o território rural nacional. Aqui foi especialmente considerado o rural do Estado do Pará e sudeste paraense, que se encontram sob constantes disputas fundiárias, crescente grilagem de terras, descaracterização das terras públicas e altas taxas de desmatamento. Como se trata de um cadastro nacional, os efeitos das políticas públicas podem se aplicar a outros territórios brasileiros ainda que estudos regionalizados possam revelar diferentes fragilidades da política.

Antes de propriamente analisar o cadastro, será realizada uma historicização dos dispositivos ambientais e fundiários brasileiros. Através de um resgate histórico das relações entre território, direito e regime econômico-político vigentes, pode-se pensar sobre o controle da terra através dos diferentes dispositivos administrativos utilizados. A trama entre direito e território se renova e a partir do mapeamento de áreas é possível ampliar as formas de controle.

Será realizada uma apresentação do CAR demonstrando onde se originou o instrumento, quais as regulamentações e instituições participantes, e os desafios que os estados pioneiros no CAR enfrentaram. Dito isso, serão problematizados os efeitos das políticas públicas através do aporte teórico da antropologia das políticas públicas. Com o intento de promover regularização ambiental e fundiária no Brasil, cindindo tecnologias de mapeamento subsidiadas pelo novo Código Florestal brasileiro, a política atua através de novas formas 
de controle no território rural brasileiro e de quantificar e negociar passivos ambientais. Para tanto, é foco do trabalho compreender alguns efeitos que extrapolam a política pública, intencionais ou não, tais como efeitos fundiários pela sobreposição de terras, grilagem através de documento público federal de cunho ambiental e outros.

\section{HISTORICIZAÇÃO DOS DISPOSITIVOS FUNDIÁRIOS E AMBIENTAIS NO BRASIL}

Por meio de um resgate histórico das relações entre território, direito e regime econômico-político vigente é possível pensar o controle da terra através de diferentes dispositivos administrativos, assim como a renovação da trama entre direito e território a partir do mapeamento de áreas. A exemplo da metodologia proposta por Michael Dwyer (2013), se faz necessária aqui uma historicização da formalização das terras para compararmos a produção de mapas em diferentes tempos e analisar suas consequências. $O$ território e a propriedade rural são imprescindíveis para a expansão da agricultura e as políticas de mapeamento incidem sobre esses espaços valorizados pela produtividade agrícola e como ativo financeiro extraído da propriedade da terra. Ao mesmo tempo, os espaços protegidos na propriedade são medidos e também compõem a trama das legislações, disciplinando onde se devem manter florestas e matas nativas em pé dentro das propriedades.

No entanto, desnaturalizar as relações territoriais existentes hoje e compreendê-las a partir de uma perspectiva histórica potencializa e enriquece análises do espaço rural e das relações entre território, direito e regime econômico-político, de maneira que o CAR pode alcançar novas compreensões através de uma genealogia da formalização dos contratos de terras e da proteção ambiental.

O Império Colonial (1530-1815) instituiu o regime das sesmarias, das terras devolutas e das terras públicas que se mostrou ineficiente para regular as propriedades públicas e privadas. Tendo em vista que a experiência em Portugal foi a do regime sesmarial, a transferência do regime para o Brasil pareceu solução conhecida. Os principais problemas que a administração colonial enfrentava eram as dificuldades em mensurar as terras e a falta de demarcação de terras pelos sesmeiros que não queriam pagar o foro. (SILVA, 1996) Mesmo as terras que possuiam algum tipo de medida e de registro dominial, tinham na barreira da medição seu maior desafio: 
Na maioria dos casos era difícil estabelecer a exata localização e dimensões das terras pleiteadas, pois as indicações relativas à localização eram bastante vagas (até onde conseguir aproveitar, toda a terra que se achar devoluta e sem dono; toda terra que nestes meios se acharem) favorecendo o esticamento de seus limites. Um dos problemas que dificultavam a localização das cartas é que algumas faziam referência a acidentes geográficos ou até fatos históricos (onde mataram o Varella), que possivelmente só eram identificáveis pelos contemporâneos, mas desconhecidos posteriormente, outras traçavam referencias tão artificiais que criavam problemas para os próprios contemporâneos. [...]

O medidor enchia o cachimbo, acendia-o e montava o cavalo, deixando que o cavalo marchasse a passo. Quando o cachimbo se apagava, acabando o fumo, marcava uma légua. Como quem dominava a técnica de demarcação eram pilotos de navios (únicos a saber usar a bússola e poder assim estabelecer rumos corretos das linhas a serem traçadas) e estes escasseavam, não era fácil proceder demarcações, o que tornou o regime jurídico das concessões das cartas das sesmarias sistematicamente desobedecido e as terras sesmariais sistematicamente intrusadas. (TRECANNI, 2001, p. 41)

A falta de controle sobre as terras e a cessão de sesmarias em terras já ocupadas deu espaço para o costume jurídico até hoje presente: a posse. Com a falência do sistema sesmarial, o grande número de terras devolutas (devolvidas ao Império) e a confusão territorial causada pela falta de medição, a Lei da Boa Razão de 1769 inaugurou parâmetros para aquisição de terras devolutas pela posse através dos critérios da cultura efetiva (racionalidade no uso da terra) e da antiguidade. O sistema sesmarial foi pressionado pelo senhoriato rural, entre sesmeiros irregulares e posseiros, que se uniram contra a metrópole e as insistentes cobranças de concessões de foros que obrigou o senhoriato rural a realizar a regularização de terras. (SILVA, 1996)

Ainda no Império, a consequência da falta de clareza sobre a definição de terras devolutas e incapacidade de fiscalização do Estado sobre as terras, foi que a lei de 1850 abriu as portas para grilagem, prática problemática antes da promulgação da lei. (SILVA, 1996, p. 158)

O excesso de tentativas para burocratizar o espaço rural mesmo sem medições adequadas, levou o processo fundiário a ser marcado pela posse em detrimento do registro, beneficiando latifúndios dependentes de oligarquias locais que mantinham suas propriedades através da ameaça e da violência. A 
triangulação "lei, burocracia e violência" era (e parece que continua sendo) a chave da luta pela terra, segundo Joe Foweraker (1981). Desta maneira, a falta de regularização fundiária dava poderes às oligarquias locais para beneficiar o senhoriato rural com as melhores terras, sobrepondo territórios concedidos e de posseiros, que em sua maioria eram camponeses pobres sem acesso às terras que desbravavam áreas de fronteira agrícola. Ao tornarem essas terras produtivas, tais camponeses eram expulsos pelos latifundiários que passavam a explorar os recursos daqueles espaços ou vendê-los. (FOWERAKER, 1981)

No Brasil, tradicionalmente a terra é titulada muito antes de ser ocupada. Regiões inexploradas no interior têm, provavelmente, uma complexa história legal, e muitas áreas dentro dessas regiões são certamente registradas mais de uma vez. Durante a administração colonial, o território foi concedido por lei, antes mesmo que sua extensão pudesse ser avaliada com qualquer grau de acuidade. [...] Durante os 28 anos após a Independência, não tinha Lei de Terras, e o que ocorreu era ocupação pura e simples. Quando começou a história da Lei de Terras, foi conferido pleno direito de propriedade nos títulos e requerimentos anteriores, derivados da sesmaria, como também a coragem do pequeno fazendeiro, que civilizou o interior, fazendo a terra produzir. E nunca mais desfrutaria ele, novamente, de reconhecimento do Estado. (FOWERAKER, 1981, p. 121)

Após o período da Independência do Brasil, sob a nova dinâmica de Estado ainda voltada para o senhoriato rural e atenta a essas demandas, o dispositivo para ampliar o mapeamento no Brasil foi a Lei de Terras de 1850. Lei que objetivava a regularização de ocupações e de posses para diferenciar as terras públicas das terras privadas e favorecer um maior controle sobre o território e os recursos.

Entre os demais objetivos desta lei estavam a extinção da figura jurídica da sesmaria, o disciplinamento da propriedade, da posse e do uso da terra e o equacionamento da transição das relações de trabalho à ordem jurídica e social determinada pela dinâmica do mercado - a extinção do tráfico de escravos, a divisão do trabalho e a evolução capitalista. (NEVES, 2003) A lei buscava ser um marco para apropriação territorial, tendo em vista que a porção de território ocupado, segundo o Censo Agropecuário de 1920, era ínfima: 79,4\% de terras devolutas e $20,6 \%$ de terras cultivadas. $O$ que se queria era regularizar as propriedades dos terrenos já ocupados e determinar normas de acesso as terras devolutas. (SILVA, 1996) Porém, o processo de implementação da Lei de Terras, 
regido pelo senhoriato agrário, reafirmou a tradição colonial do monopólio da terra e da força de trabalho ao invés de promover uma reforma da propriedade fundiária.

A extinção do tráfico [de escravos] e a Lei das Terras resultaram [...] de um contexto mais abrangente e internacional da divisão do trabalho que a evolução capitalista impunha além de expressarem a tática de acomodação de interesses e conciliação política do Império, traduzindo a reação das elites políticas postadas no Conselho de Estado às pressões externas, admitindo o fim da escravidão no horizonte visível. (NEVES, 2003, p. 27)

A Lei de Terras não obteve êxito no disciplinamento do território brasileiro, principalmente no controle das terras públicas, sendo a grilagem de terras um dos fenômenos que mais comprometeram os objetivos da lei. Tal fenômeno burlou o controle de terras, de modo que estas eram apropriadas, não registradas em cartório e seus documentos eram "grilados" (envelhecidos), forjando a veracidade para dominar espaços no território de forma irregular e através de documentação, mas sem o devido registro legal da terra. Além disso, o controle era estabelecido por cartórios e a propriedade registrada era feita pela folha pessoal determinando que tal pessoa é proprietária de um território. Essa folha pessoal se revelou altamente conflitiva, pois em diversos lugares haviam sobreposições de interesses entre pedaços de terra registrados de forma imprecisa e sobreposta.

Outro dispositivo importante foi o Registro do Vigário, que obrigava aos possuidores se registrarem de forma auto-declaratória, com finalidade de simples conhecimento estatístico das terras e sem intenção de cadastro. No entanto, o que aconteceu foi que o Registro do Vigário foi apresentado como prova de domínio de particulares sobre terras, em geral, devolutas.

Embora a lei fosse clara no sentido de negar-lhe a validade como título porque seria sobremodo estranho que ao particular se conferisse a liberdade de criar seu próprio domínio sobre determinada porção do território pátrio, o Registro do Vigário teve uma importância que talvez nenhum outro dispositivo da lei de terras igualou. (SILVA, 1996, p. 175)

Enquanto o Estado realizou uma estatística das terras, seus cadastrantes interessados no domínio da terra ressignificaram a funcionalidade em benefício próprio e a política apresentou efeitos fundiários muito diferentes do esperado, favorecendo uma espécie de grilagem pela compra e venda de terras 
com o uso do Registro do Vigário. A proximidade desse dispositivo com o CAR se revela pelo cadastro autodeclaratório, e os resultados desse tipo de política, segundo Ligia Silva (1996), são uso indevido dos instrumentos.

No que tange aos códigos de proteção às florestas, o primeiro Código interessado em limitar o direito de propriedade foi o Código Florestal de 1934, que inaugurou a reserva da "quarta parte" da propriedade para manutenção das florestas e de mato nativo, com o intuito de assegurar que as propriedades não acabassem com as florestas. A "quarta parte" da propriedade inaugura o que hoje se conhece como Reserva Legal, sendo o primeiro mecanismo direcionado à proteção ambiental/florestal. O período de vigência desse Código Florestal (1934) foi marcado pela criação de diversos outros Códigos, na tentativa de centralizar a estrutura material do Estado através do aparelho tecnoburocrático das legislações. ${ }^{2}$ (DRAIBE, 1985) E por ser um Código pioneiro mas pouco restritivo e aplicável, o Código Florestal foi substituído em 1965 pela Lei Federal 4.771, e determinou os limites mínimos de Área de Preservação Permanente (APP) e os percentuais mínimos de Reserva Legal (RL). Nesta época definiu-se a APP de 5 (cinco) metros de para rios de menos de 10 (dez) metros de largura, igual à metade da largura dos cursos que meçam de 10 (dez) a 200 (duzentos) metros e de de 100 (cem) metros para todos os cursos cuja largura seja superior a 200 (duzentos) metros. A reserva legal era de 50\% das propriedades na Amazônia e 20\% das propriedades nas demais regiões do País. O Código Florestal de 1965, em vigor até 2012, teve o reforço da Lei dos Crimes Ambientais (Lei ${ }^{\circ}$ 9605/1998).

Voltando à década de 1960, o dispositivo fundiário criado foi o Estatuto de Terras de 1964, que, complementado pela Lei de Registros Públicos (Lei 6.015/1973), modificou o processo de transferência da propriedade de imóveis rurais, processo este dificultado pela falta de confiança nos cadastros imobiliários.

Até a promulgação da Lei de Registros Públicos, os atos de transmissão de domínio imobiliário eram realizados por meio de transcrições em livro próprio e em ordem cronológica, fazendo menção precária ao título do transmitente e à qualificação

2 "A elaboração dos Códigos e regulamentações dos serviços de utilidade pública afetos à vida econômica visavam, desde logo, a atualizar uma legislação ou de caráter incipiente, ou que já se tornara obsoleta em face da modernização do país. Em 1934, foram promulgados os importantes Código de Água e Código de Minas; entre 1931 e 1934, definiu-se a legislação básica de regulamentação dos Serviços de Radiocomunicações em Território Nacional. O Código Brasileiro do Ar é de 1938; o de Caça e Pesca e o de Florestas são de 1934. Foram elaborados, também, o Código da Propriedade Industrial, a Lei das Sociedades por Ações e o anteprojeto do Código de Obrigações. [...] Isso não definia apenas um quadro legal de legitimação do intervencionismo estatal; abria espaço para que ele avançasse para formas ainda mais profundas: a propriedade da União sobre recursos estratégicos passíveis de exploração industrial foi o ponto de partida para a presença do Estado-empresário nessas áreas fundamentais para o desenvolvimento econômico." (DRAIBE, 1985, P. 85) 
do imóvel e das partes. Com o advento da LRP, cada imóvel passou a ter o seu histórico concentrado em um único documento, a matrícula, o que confere, decerto, maior controle e segurança. (MORAES, 2014, p. 88)

A lei inaugurou a matrícula do imóvel como pré-requisito do registro, o que seria um primeiro passo para o completo cadastro imobiliário, adotando como ponto referencial o imóvel, independente de sua titularidade. A matrícula substituiu o fólio pessoal ou folha pessoal para o fólio real ou folha do imóvel, inovando o sistema de registro imobiliário. Em outras palavras, a propriedade deixa de estar atrelada a alguém e passa a estar atrelada a um espaço físico.

O cadastro de imóveis rurais (art. 46 do Estatuto da Terra) é criado para melhorar a tomada de decisões políticas, tendo em vista que a matrícula do imóvel passou a solicitar dados da família, natureza da posse e forma de administração, valor das benfeitorias, equipamentos e instalações existentes, condições da exploração e uso da terra. A conveniência desse novo modelo era o melhor redirecionamento da atuação estratégica do Estado. Com isso, foi criado o Sistema Nacional de Cadastros Rurais, com finalidade parafiscal dos cadastros.

A matrícula transformou a produção do cadastro e deu maior precisão e controle às transações e registros de imóveis rurais, possibilitando uma interessante conexão entre propriedade e proteção ambiental por meio da Reserva Legal (Lei 7803/1989). Essa conexão é a exigência de averbação ou registro de Reserva Legal na matrícula do imóvel, o que convenia a propriedade com a reserva florestal, garantindo segurança jurídica da Reserva Legal mesmo sob a venda/aluguel/arrendamento do imóvel. No entanto, o Novo Código Florestal (2012), de acordo com o art. 18, dispensa averbação da Reserva Legal na matrícula do imóvel, de modo que a Reserva Legal deve ser registrada apenas por meio do CAR, sem a antiga necessidade de averbação. $O$ retrocesso em matéria ambiental tende a ser muito significativo, tanto pelo caráter auto-declaratório do Cadastro Ambiental Rural quanto pela perda do mecanismo de averbação da Reserva Legal na matrícula do imóvel, que consolidava segurança jurídica à Reserva Legal através da matrícula. Tais transformações acabam por separar a base de regularização ambiental da base de regularização fundiária, o que causa desproteção jurídica e promove uma estrutura ambiental que desobriga proprietários/posseiros dos passivos ambientais anteriores.

Em matéria legal, o novo Código autorizou a regularização ambiental dos imóveis rurais com passivos anteriores a 2008 assim como estabeleceu parâmetros mais flexíveis para as áreas consolidadas em APPs e Reserva Legal, uma vez que admite o cômputo das APP no cálculo do percentual da RL para todos os imóveis, bastando estar no CAR, além de alterar o cálculo de faixas 
marginais de proteção ao longo de cursos de água, entre outras mudanças, diminuindo o grau de proteção ambiental. Para se ter uma ideia da diminuição da proteção, o estudo de Britaldo Soares Filho e outros (2014) apresenta que o passivo ambiental e as áreas a serem recompostas tiveram uma redução de $58 \%$ com as mudanças implementadas pelo Código Florestal, com maior redução nos estados de Mato Grosso, Pará, Minas Gerais e Bahia.

Ao realizar a genealogia dos mecanismos de formalização do controle da terra no Brasil, se percebe a Lei de Terras destituindo a figura jurídica da sesmaria para regularizar como negócio jurídico as ocupações e posses para adaptação à economia capitalista liberal; a Lei de Registro Público desfocando o negócio jurídico para a matrícula do imóvel e o folio real; e o Novo Código Florestal dispensando averbação da Reserva Legal na matrícula do imóvel, devendo ser registrada apenas por meio do CAR através do georeferenciamento de todas as propriedades do Brasil.

Uma série de legislações implementadas e situações legais de sobreposição de documentação, desde os tempos das sesmarias, por problemas de medição ou por duplicação de documentação pelas autoridades provocam grande confusão legal, inclusive com documentações que não comprovam titularidade dominial - como as produzidas no Registro do Vigário - utilizadas para comprovação de domínio, instaurando regime fundiário frágil, favorecendo grileiros, governantes e cartórios a expulsar camponeses de regiões de interesse do grande capital.

O conjunto de leis, governando o acesso e ocupação de terras, é imensamente complexo, sendo que inúmeras leis, decretos-leis, regulamentos, instruções, portarias e explicações nunca foram unificadas. Diz-se que no Brasil estão em vigor 120 mil leis, e a única que falta é a lei para obedecê-las. (FOWERAKER, 1981, p. 147)

Um país que por diferentes formas vem sendo ocupado, se transforma no país do esquadrinhamento minucioso por meio de dispositivos cada vez mais apurados. A questão é de que maneira esses dispositivos administrativos, com objetivos aparentemente democratizantes, vem sendo manipulados até favorecer os mais fortes num quadro em que camponeses, agricultores familiares, quilombolas, indígenas, comunidades tradicionais aparecem como obstáculos à expansão indefinida do capital. 
A sucessão de cadastros e de mapeamentos ampliam o projeto de simplificação territorial (SCOTT, 1998) a partir da consolidação de informações, na melhora na capacidade de controle, no atrelamento do crédito agrícola à adesão ao mapeamento e na ampliação tecnológica através do georeferenciamento. A renovação dos métodos de composição da malha fundiária encontra na proteção ambiental um aliado para a melhoria da fiscalização do desmatamento e dos imóveis rurais. Entre cartórios, políticos e proprietários de terra, o anúncio de tecnologias como as de georrefereciamento são o prelúdio de novas formas de controle do território, mas não necessariamente de ampliação da segurança jurídica dos povos tradicionais, das comunidades rurais e das florestas.

\section{O CADASTRO AMBIENTAL RURAL}

A presente seção apresentará o Cadastro Ambiental Rural (CAR), pensando a partir dos principais regramentos e do instrumento de cadastramento e mapeamento de todas as propriedades e posses rurais brasileiras. O CAR é registro público eletrônico de âmbito nacional, obrigatório para todos os imóveis rurais, que integra as informações ambientais das propriedades e posses rurais numa base de dados com fins de monitoramento, planejamento ambiental e econômico e combate ao desmatamento, conforme o artigo 29 da Lei 12.651/2012.

O CAR foi regulamentado pelo Decreto 7.830/2012, que dispõe sobre o Sistema de Cadastro Ambiental Rural (Sicar), sobre o próprio Cadastro Ambiental Rural (CAR) e estabelece normas de caráter geral para os Programas de Regularização Ambiental (PRA), complementada pelo Decreto 8.235/2014. Além desses, a Instrução Normativa do Ministério do Meio Ambiente $n^{\circ} 2$ e 3 dispõem sobre procedimentos para integração, execução e compatibilização do Sicar e procedimentos gerais do CAR e sobre a integração e segurança da informação do Sicar.

Para realizar o cadastro, o cadastrante necessita da identificação do proprietário/possuidor rural, da comprovação da posse ou propriedade e da identificação do imóvel por meio de planta e memorial descritivo, contendo a indicação das coordenadas geográficas com pelo menos um ponto de amarração do perímetro do imóvel, informando a localização dos remanescentes de vegetação nativa, das Áreas de Preservação Permanente, das Áreas de Uso Restrito, das áreas consolidadas e, caso existente, também da localização da Reserva Legal. 
Dentro da política ambiental, o CAR está situado dentro do Programa de Regularização Ambiental (PRA), disposto no Decreto 8.235/2014. O PRA é o conjunto de ações a serem desenvolvidas por proprietários e posseiros rurais com o objetivo de adequar e promover a regularização ambiental tendo como estratégia formas de recuperação, recomposição, regeneração ou compensação de Áreas de Preservação Permanente, de Uso Restrito e de Reserva Legal no interior dos imóveis rurais, objetivando enquadrar situações de passivos ambientais dos produtores rurais e regularizar as multas e passivos ambientais.

O PRA possui como instrumentos, além do CAR, o termo de compromisso entre agricultores e Estado, o Projeto de Recomposição de Áreas degradadas e as Cotas de Reserva Ambiental. Os passivos ambientais podem ser negociados através de acordos, de projetos de recomposição e de cotas de reserva ambiental. Após a adesão do produtor/posseiro rural ao PRA, suspende-se as multas para cumprir as obrigações compromissadas, resolvendo antigas multas ambientais. As infrações cometidas antes de 22 de julho de 2008 não poderão ser autuadas caso o proprietário ou possuidor tenha assinado termo de compromisso para sua regularização ambiental.

O prazo para os cadastrantes entrarem no sistema é 31 de dezembro de 2019, após uma série de prorrogações já realizadas, o que significa que cadastros novos estão sendo aceitos na plataforma do Sicar. Após o cadastrante inscrever posse ou propriedade no sistema, deve aguardar as Secretarias de Meio Ambiente fazerem a análise do registro para validação de seus dados e de suas áreas protegidas. Segundo o artigo 29 do Novo Código Florestal, o cadastro no CAR não é considerado título para fins de reconhecimento do direito de posse ou propriedade. Além disso, a inscrição no CAR é autodeclaratória e permanente, sendo responsabilidade do declarante as informações declaradas, incorrendo em sanções penais e administrativas se forem declaradas informações parciais ou totalmente falsas, enganosas ou omissas. Contudo, enquanto não houver análise e manifestação do órgão competente acerca de pendências ou inconsistências nas informações, a inscrição é considerada efetivada e ativa para todos os fins previstos em lei. Caso a declaração do cadastrante incidir sobre outro imóvel rural, terras públicas ou áreas consideradas restritivas, o Sicar envia alerta à Central do Proprietário/Possuidor por meio de filtros automáticos. É de se destacar na nova legislação que se o proprietário ou possuidor de imóvel tenha reserva legal conservada e inscrita no CAR superior à exigida pela lei, poderá utilizar a área excedente para fins de servidão ambiental, cotas de reserva ambiental e outros instrumentos da lei, como recebimento de pagamento por serviços ambientais. 
As principais instituições que gerenciam o Sicar são o Ministério do Meio Ambiente do Governo Federal e o Serviço Florestal Brasileiro (SFB), que é responsável em nível federal por apoiar a implantação, gerir e integrar as bases de dados ambientais do CAR junto aos Órgãos Gestores do Sicar nos estados. Outra instituição chave é a Universidade Federal de Lavras (Ufla) de Minas Gerais, através de apoio técnico desde a concepção do sistema até cursos à distância de capacitação para acesso ao Cadastro Ambiental Rural, realizando cursos para técnicos das secretarias estaduais de todo o Brasil, para instituições ligadas ao setor rural brasileiro, para cadastrantes individuais e interessados em geral.

Antes de ser institucionalizada, a política do CAR teve início através de iniciativas de ONG's internacionais no Mato Grosso e logo após no Pará. O objetivo dessas organizações era de conciliar a produção agrícola com preservação ambiental através de instrumentos de georreferenciamento, tendo como objetivo mostrar para os consumidores internacionais de soja que as fazendas brasileiras conciliam agricultura e floresta através da proteção ambiental. Assim, através de alianças nos estados do Mato Grosso e Pará, os produtores, a ONG The Nature Conservancy (TNC) e a empresa Cargill iniciaram processos de licenciamentos ambientais e mapeamento dos espaços produtivos para reconhecimento da agricultura sustentável praticada pela empresa. $\mathrm{O}$ primeiro dispositivo estatal criado para atender essa demanda foi o SLAPR (Sistema de Licenciamento Ambiental de Propriedades Rurais), licenciando produtores à atividades agrícolas ao mesmo tempo que demarcando áreas protegidas dentro das propriedades através da tecnologia do geoprocessamento. Através do sistema, era possível emitir a Licença Ambiental Única (LAU) ${ }^{3}$ e estar regularizado ambientalmente para realizar atividades agrícolas. (AZEVEDO, 2009) Essas iniciativas de emissão de licenças tiveram como pretexto inúmeras denúncias de desmatamento em regiões amazônicas e no Mato Grosso.

Em 2004 o Pará criou a LAR (Licença Ambiental Rural) também com o intuito de regularizar produtores na questão ambiental. Os grandes apoiadores das políticas de licenciamento ambiental foram empresas do agronegócio como Cargill e ONG's como TNC, Conservation Internacional, Ipam (Instituto de Pesquisa Ambiental da Amazônia), Imazon (Instituto do Homem e Meio Ambiente da Amazônia), tendo em vista o aumento significativo do

3 A Licença Ambiental Única (LAU) foi criada através da Lei Complementar Estadual $\mathrm{n}^{\circ} 38$ de 1995 que estabeleceu o Código Ambiental do Mato Grosso. 
desmatamento na região e a urgência da regularização por parte dos produtores. Em 2008 foi publicado no Pará o Decreto Estadual 1148/2008, instituindo o CAR como um dos instrumentos da Política Estadual de Florestas e Meio Ambiente, tornando obrigatório o cadastramento de todo imóvel rural localizado no estado do Pará.

Tanto no Mato Grosso quanto no Pará, o sistema de licenciamento tinha natureza autodeclaratória, fomentado pela necessidade de certificação para o mercado mundial de commodities e a moratória da soja de 2006 , onde os produtores precisavam provar que suas posses/propriedades eram sustentáveis e não oriundas de processos de desmatamento. Assim, com o desafio de "desburocratizar" os dispositivos ambientais, a parceria entre agronegócio e ONG's foi crucial para iniciar as regularizações dos produtores e contemplar a demanda conciliatória entre produção agrícola e conservação ambiental. Nessa mesma seara, a discussão do Novo Código Florestal acontecia com forte apelo dos setores do agronegócio para a desburocratização das leis ambientais, para a flexibilização das licenças ambientais e da diminuição das áreas com restrições ambientais e reconhecimento jurídico das áreas consolidadas (áreas antropizadas e com cultivo agrícola). E foi sob essas tensões que o debate do Código Florestal foi conduzido entre pesquisadores, empresários do ramo do agronegócio, parlamentares, ONG's, lideres e movimentos sociais, tendo em vista a crescente produção agrícola esperada pelo mercado mundial e a necessidade de flexibilização das leis ambientais, sob o argumento de conciliação entre proteção ambiental e produção agrícola. (CHIAVARI; LOPES, 2016)

O CAR foi aprovado através da lei 12.651, de 25 de maio de 2012, também conhecida como Novo Código Florestal, substituindo a lei 4.771/1965. A política se propõe a ampliar o uso de registros cartográficos pelo uso do GPS (Global Positioning System), abrindo nova forma de fiscalização e de planejamento através do georreferenciamento para o Sistema Nacional de Informação sobre Meio Ambiente (Sinima). O Brasil comprou uma megafotografia do território nacional, através de uma parceria entre Ministério do Meio Ambiente, Caixa Econômica Federal, o Banco Alemão para o Desenvolvimento (KfW) e a Agência de Cooperação Alemã (GIZ), e a partir dela é possível cadastrar os pontos de GPS das propriedades brasileiras e realizar a política ambiental.

Diante disso, renova-se uma trama entre direito e território, onde a partir do mapeamento de áreas é possível renovar as formas de controle e aperfeiçoar o panóptico, ao mesmo tempo que regularizar o território significa ajustar situações de ilegalidades em matéria ambiental e, pelas características de autocadastramento e baixa verificação de dados, abrir espaço para grilagem 
de terras. O CAR está evidenciando inúmeras sobreposições em terras públicas - como terras indígenas, assentamentos, unidades de conservação - e está se tornando um instrumento para "grilagem" de posses em terras públicas e de compra e venda. Como aponta Eliane Moreira (2016), um documento de ordem ambiental sem finalidade fundiária está sendo usado para legitimar e comprovar propriedade da terra.

\section{ANALISANDO OS EFEITOS DA POLÍTICA DO CADASTRO AMBIEN- TAL RURAL}

Dentro dos estudos sobre análise das políticas públicas, uma abordagem que vem ganhando importância é a da antropologia das políticas públicas. O trabalho de 1997 de Cris Shore e Susan Wright, denominado "Anthropology of policy: critical perspectives on government and power", inaugura uma antropologia voltada para as políticas de governo e de poder, com especial atenção às categorias criadas pelo Estado, para as tecnologias de governança e para a política enquanto linguagem e poder. Assim, a antropologia da política centrou esforços nas políticas públicas e no Estado, trazendo elementos culturais para dentro da análise e que diferentes culturas produzem diferentes Estados, questionando a visão weberiana e marxista de que só o Estado produz cultura. A estrutura da autoridade burocrática depende de repetir encenações na prática cotidiana para sua reprodução e reconhecimento, às vezes silenciosamente aproveitando práticas já constituídas pela população, às vezes mostrando sua presença e seu poder.

Com grande influência do filósofo Michel Foucault e da noção de biopolítica, a governança assume o papel da "condução das condutas" e as políticas públicas são uma das possibilidades de estudo. A antropologia das políticas públicas tenta estudar "através das políticas públicas", e não a política pública em si, tentando capturar a existência, a prática cotidiana e os efeitos das políticas públicas, possibilitando compreender a mudança de estilo dos sistemas de governos. Os conceitos sobre Estado e as nuances em relação às diferenças de governamentalidade atuais se tornam centrais na análise, assim como a troca do poder disciplinar para a biopolítica, que abrange o poder disciplinar mas está mais interessado no controle da economia como forma ideal da gestão da população. Michel Foucault (2008) observa que os governos passaram a "fazer viver" a economia da população, atuando na gestão das condutas como produtor de subjetividades na medida do interesse da gestão, através de categorias que pos- 
sam servir para a sociedade. Essa construção de governo passa a servir como referência até naturalizar-se na população enquanto categoria a-histórica e parâmetro de normalização à sociedade. É importante enfatizar que governar a biopolítica é observar as práticas cotidianas e dar vazão à potencialidades já existentes na sociedade. "Conduzir as condutas" (FOUCAULT, 2008) incita antes observar as condutas já existentes, incentivando ou promovendo categorias para a população

José Renato Porto (2016) sugere que a noção de "agricultura familiar" é uma categoria que possui uma história e que induz a população rural a enquadrar-se nessa forma-estado. Assim, tornar-se "agricultor familiar" para a sociedade está carregado de significados, que por sua vez conecta-se a uma série de políticas públicas, dando sentido ao trabalhador. Ou ainda, quando o trabalhador não possui as características de "agricultor familiar", sua entrada para quaisquer políticas de incentivo ou de previdência social se torna anormal para o governo. No caso do CAR, a categoria "posseiro/proprietário rural" é responsável por realizar o mapeamento e o cadastro informando aos registros ambientais do país as parcelas de terra com as áreas protegidas, as reservas legais e compromete-se, caso tenha algum passivo ambiental, a regularizar suas áreas de preservação dentro de sua propriedade.

A partir do cadastro autodeclaratório é que os governos farão suas fiscalizações e regularizações, criando uma situação de regularidade e/ou regularização que até então não existia. Para aquele "posseiro/proprietário rural" que possui passivos ambientais anteriores a junho de 2012, a nova legislação possibilitou a regularização. Se antes do CAR o "posseiro/proprietário rural" possuía um passivo ambiental e possivelmente respondia a processo criminal na seara ambiental, após a adesão ao CAR cria-se uma situação onde a multa e o passivo ambiental (poder disciplinar) dão lugar à regularização ambiental e a negociação de passivos ambientais (biopolítica). (FOUCAULT, 2008)

Além da problematização das categorias que o Estado produz, as tecnologias de poder são intenso foco da antropologia das políticas públicas, ao tentar compreender de que formas e sob que condições hoje o governo opera para e com as populações. Assim, o governo passa a necessitar de instrumentos de medição aptos a controle e aptos a normalização, tais como censos, biometrias, cadastros, mapeamentos.

Para tentar compreender o Estado na modernidade, a noção de governamentalidade tenta aportar as modificações e características na forma-estado, para tentar compreender na sequências as tecnologias de poder que operam os Estados nas políticas neoliberais. Assim, como características gerais, Michel 
Foucault (2008) apresenta a governamentalidade como um conjunto formado por instituições, procedimentos, análises e reflexões, cálculos e táticas que permitem o exercício do aparato de poder, tendo a população como seu foco principal; a formação de um forte aparato governamental baseado na soberania e disciplina, e a formação de uma rede complexa de saberes; o resultado do processo, onde o estado de justiça da Idade Média se transforma gradualmente em Estado administrativo "governamentalizável".

A visão de Estado como monolítico e coeso em sua tomada de decisões parece uma das possíveis consequências das tradições de estudo sobre o Estado, e que em alguma medida se repete na análise de Michel Foucault. Ainda, a sensação de pouca mobilidade para a categoria "população" e uma regência excessiva estatal sugerem especial atenção para o presente estudo. Apostando que o Estado possui autonomia relativa/relacional em relação à população, como Bob Jessop (2009) buscando em Nicos Poulantzas apresentou, a característica fundamental da potência de governamentalidade e do poder em Michel Foucault ainda permanece intacta, porém os movimentos e flutuações das ações políticas e das frações de classes disputando a estrutura estatal, além do alcance das políticas estatais, nem sempre almejam aquilo que prometem, quando não acabam por realizar ações não esperadas pelas políticas.

A política pública traz consigo uma série de dispositivos e de tecnologias que os gestores da política imaginam trazer efeitos para os territórios. Analisar os efeitos de políticas públicas é foco desse trabalho e interessa investigar que o Cadastro Ambiental Rural vem trazendo uma série de efeitos, alguns esperados e almejados, outros não diretamente esperados mas previstos enquanto possíveis empecilhos. Entre o que é esperado e o que efetivamente acontece, há um expressivo campo de análise e nos permitirá avançar as discussões sobre as políticas públicas, Estado e cadastros.

James Scott (1998) analisa com grande acurácia processos de mapeamento e cadastramento, na tentativa do Estado de simplificar o território para nele incidir, sem que isso necessariamente contemple as complexidades do território. Diferentes dispositivos são acionados para melhorar o registro e a cobrança de impostos através de técnicas de simplificação e planejamento moderno. A promessa da racionalidade moderna posta em prática é expandir controle e soberania do território, e para isso lança mão de simplificações para mensurar as parcelas de terra. Dentro da ideia de Estado moderno, o suporte científico torna-se central para o exercício do domínio e produção de simplificação radical e legibilidade do território, para torná-lo calculável, remunerável e, acima de tudo, previsível. 
A limitação do conhecimento do Estado, em parte, era devido à complexidade e variedade da produção local. Mas não era essa a principal razão. A forma de taxação coletiva significava que era do interesse dos oficiais locais deturpar sua situação para minimizar sua taxa local e a carga recrutada. Para isso, eles precisavam minimizar a população local, subestimar a área cultivada, esconder novos lucros comerciais, exagerar na perda das lavouras depois das tormentas etc. $O$ ponto do mapa cadastral e registro de terras era precisamente eliminar o fiscal feudal e racionalizar a receita fiscal do Estado. Assim como os cientistas da floresta necessitavam um inventário de árvores para realizar o potencial comércio de florestas, assim o fiscal precisa de um inventário da propriedade da terra para alcançar o máximo rendimento de receita sustentável (tradução livre). (SCOTT, 1998, p. 38)

O uso de instrumentos aptos a deter o território para melhor governá-lo tem como objetivo a redivisão da propriedade em menores áreas, para aperfeiçoar o sistema de arrecadação estatal. Segundo o autor, os senhores feudais fraudavam a sua produtividade real escondendo-se atrás de uma malha coletiva de atividades, e assim um novo recorte através de mapas cadastrais renova a capacidade de domínio do território. A condição do homem pré-moderno era de uma cegueira relativa do território, e o advento de novas técnicas parece renovar malhas de controle e fiscalização, contando com instrumentos de legibilidade cada vez mais complexos. Ainda assim, James Scott (1998) pondera que os instrumentos falham exatamente pela racionalidade altamente simplificadora que não capta a realidade do terreno, as possíveis manipulações feitas pelos cadastrantes e uma série de práticas e de modos de vida não são rastreados pelos sistemas. $O$ desafio desses instrumentos teóricos será detectar quais características que o CAR apresenta para expandir a malha cadastral e realizar a fiscalização e combate ao desmatamento; o cadastro é auto-declaratório e superou as expectativas de informações ambientais e lança mão de instrumentos econômicos como o Pagamento por Serviços Ambientais, as Cotas de Reserva Ambiental, possuindo particularidades em relação a outros cadastros e registros promovidos pelo Estado.

James Ferguson (1980) quando analisa políticas de desenvolvimento para eliminar a pobreza em áreas rurais em Lesotho através da modernização da agricultura, apresenta que as políticas "falharam" mas que produziram "efeitos colaterais" ou "efeitos-instrumento" que tornam possíveis o exercício do poder. Então, o aparato do desenvolvimento não foi uma máquina para eliminar a 
pobreza, mas sim uma máquina para reforçar e expandir o exercício do poder burocrático do Estado, que incidentalmente teve a "pobreza" como ponto de entrada.

Reduzindo intransigentemente a pobreza a um problema técnico e prometendo soluções técnicas aos sofrimentos de pessoas impotentes e oprimidas, a problemática hegemônica do "desenvolvimento" é o principal meio pelo qual a questão da pobreza é despolitizada no mundo de hoje. Ao mesmo tempo, tornando os desenhos intencionais de "desenvolvimento" tão visíveis, um projeto de "desenvolvimento" pode acabar realizando operações políticas extremamente delicadas, envolvendo o entrincheiramento e a expansão do poder do Estado institucional quase invisível, sob a cobertura de uma missão técnica neutra, à qual ninguém pode objetar. O "efeito-instrumento", então, é duplo: ao lado do efeito institucional da expansão do poder estatal burocrático, está o efeito conceitual ou ideológico da despolitização da pobreza e do Estado. (FERGUSON, 1980, p. 273, tradução livre).

O autor vai tratar da questão do poder de Estado por ponderar que mesmo com o planejamento do estado e de seus funcionários, o que acontece em um projeto que "falha" é a ampliação das relações de poder e dos circuitos burocráticos reforçados pelas políticas de desenvolvimento. Através de uma análise que questiona o estado como o único instrumento de racionalidade que controla a sociedade na execução de planejamento através de um centro de poder, James Ferguson acredita que o planejamento estatal é mais um elo da engenhosidade do poder e que outros elementos devem ser explorados para compreender os efeitos das políticas na sociedade. Para o trabalho, pensar o "efeito-instrumento" que a política do CAR é o caminho teórico a ser percorrido, tanto no que concerne a expansão do poder estatal burocrático quanto ao efeito de despolitização através da "solução ambiental" da política cadastral. A ideia a ser desenvolvida é que o CAR despolitiza a questão ambiental através de um instrumento que aparentemente gestiona a natureza, mas que parece estar mais preocupado em gerar "posseiros/proprietários rurais" regularizados para o mercado de commodities.

O que está em jogo são estratégias de controle geopolítico, onde planejamento econômico e ambiental inauguram plataforma de racionalização de recursos naturais, territoriais e econômicos através da "potência técnica" (ACSEL$\mathrm{RAD}$, 2002) a ser instaurada pelo Cadastro Ambiental Rural. Como resultados desse cadastramento, o Boletim Informativo do CAR apresenta que o Brasil já 
cadastrou 503.834.037 ha, sendo que possui 397.836.864 ha de áreas cadastráveis, ultrapassando as áreas passíveis de cadastros do Brasil. Em todas as regiões do país os cadastros realizados já superam as áreas passíveis de cadastro.

Em alguns estados chama atenção a discrepância entre o cadastro de base do Censo Agropecuário do IBGE de 2006 e o número de cadastros já realizados. No caso da região norte do país, foram cadastrados 142 milhões de hectares, sendo que são 93 milhões de hectares passíveis de cadastro. Dados de março de 2017 do Boletim Informativo do CAR demonstram que a região norte do país registra $60,73 \%$ dos hectares e $54,20 \%$ dos imóveis rurais envolvidos em sobreposição com terras indígenas; e $99 \%$ dos hectares e $24,66 \%$ de imóveis rurais envolvidos em sobreposições com Unidades de Conservação. A respeito das sobreposições em unidades de conservação, destaca-se no estado do Amazonas a presença de uma Unidade de Conservação muito extensa (cerca de 3 milhões de hectares) que foi sobreposta com outras propriedades, e esse caso justifica a porcentagem de $99 \%$ das sobreposições com Unidades de Conservação.

Os cadastros são auto-declarações dos posseiros/proprietários das terras, o que vem provocando uma série de sobreposições e situações conflituosas nos registros. Ao mesmo tempo, essas declarações alertam uma situação de avanço dos cadastros em terras públicas, terras indígenas, Unidades de Conservação. O Ministério do Meio Ambiente argumenta que há sobreposição de cadastros das terras e que isso se deve às terras irregulares que sobrepõem-se a outras terras. Além disso, o Ministério afirma que serão feitas as devidas correções.

O CAR vem sendo usado para grilagem de terras em vários lugares do país. Ao georreferenciar uma área e ter facilmente um documento provisório do Estado sobre determinada área sem necessidade de comprovação fundiária, o instrumento do CAR que possui como finalidade a regularização ambiental acaba sendo uma oportunidade de venda de terras públicas, terras indígenas, UCs e outras, passando a ser usado como um instrumento fundiário. Nessa perspectiva, a Promotora de Justiça e Professora da Ufpa Eliane Moreira traz os usos do CAR, principalmente no Pará:

O CAR jamais fora concebido como mecanismo fundiário, mas sim como mecanismo de regularização ambiental. Todavia, sempre teve por pressuposto a existência de uma propriedade ou posse válidas sobre as quais incidiria o cadastro. Ocorre, porém, que na prática este pressuposto tem sido deixado de lado e com isto o CAR passa paulatinamente a servir-se de instrumento para grilagem. [...] Num contexto em que a regra é a ausência de checagem rápida e eficiente dos títulos de propriedade e documen- 
tos possessórios, o CAR se estabelece como um sutil instrumento de apropriação de áreas públicas, sob o qual paira uma presunção de propriedade ou posse absolutamente falaciosa, que tem causado ou agravado conflitos na Amazônia. (MOREIRA, 2016, s/p)

A fusão entre regularização ambiental e fundiária tem um papel central nesse processo de georrefenciar o território. Tendo em vista que o cadastramento é autodeclaratório e que se dá através de polígonos em uma delimitação geoespacial, os efeitos da política de regularização ambiental são discrepâncias entre áreas cadastráveis e áreas cadastradas, sobreposições de territórios e o indevido uso para venda de terras e a abertura de terras públicas.

Figura 1 - Exemplo de sobreposições de CAR em Terras Indígenas e em Unidades de Conservação em São Félix do Xingu/Pará.

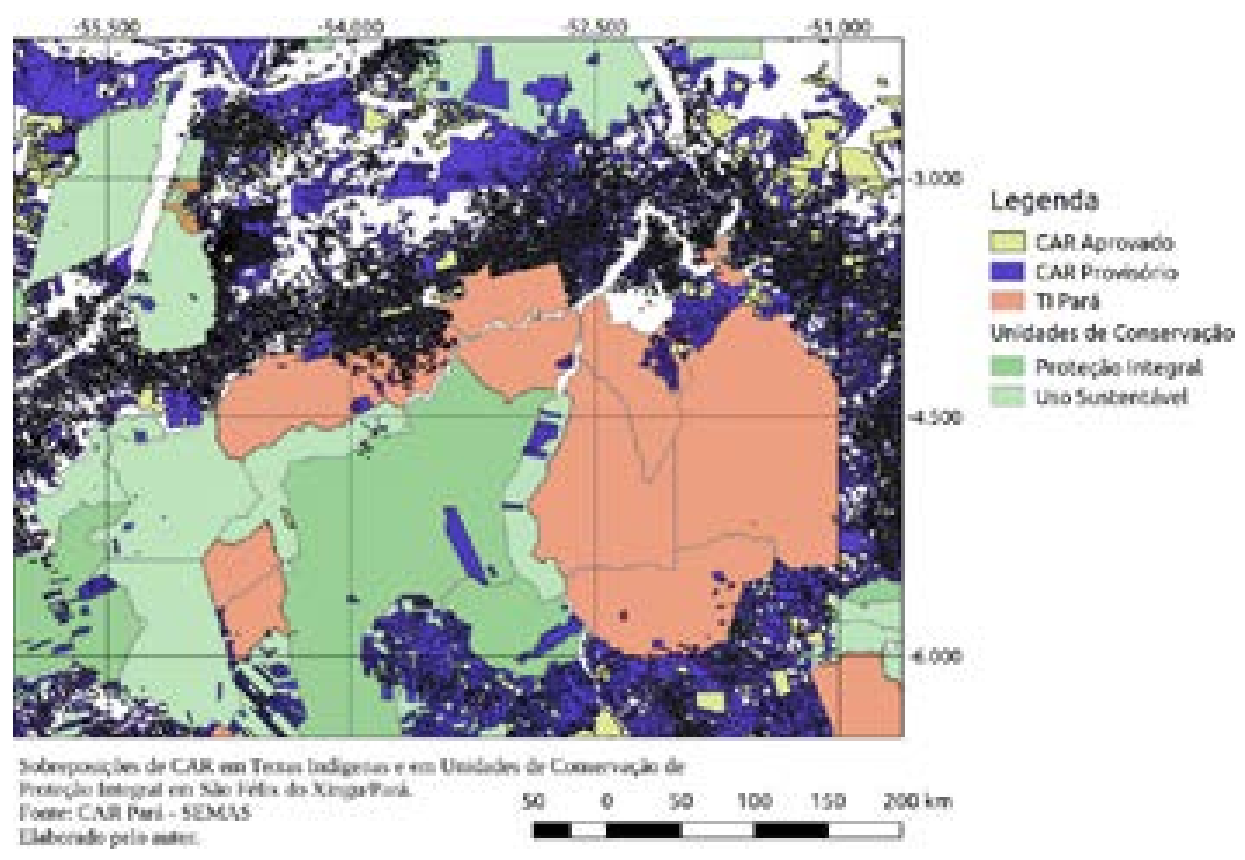

Fonte: CAR Pará - Semas (2019). Elaborado pelo autor.

A imagem acima demonstra diversos cadastros sobrepostos a terras públicas, e até que o Estado faça as correções de sobreposições, esses cadastros estão ativos. Assim, documentos de caráter ambiental avançam na esfera fundiária, sendo considerados uma espécie de grilagem de terras. Após todo um histórico de legislações, o CAR abre a possibilidade de evidenciar e alavancar 
conflitos de terras, assim como expulsar comunidades tradicionais do espaço rural.

\begin{abstract}
Quando se nota o grande emaranhado dominial, ou a inexistência documental dele, pela constatação, por exemplo, de que um território quilombola não homologado está sobreposto pela posse de uma ou várias famílias ou de uma propriedade particular, a primeira reação é pensar que o CAR nos ajuda a visualizar e a "espacializar" o problema. Isso pode até ser verdade. Contudo, é importante lembrar que a espacialização desses conflitos e de suas consequências para a própria reprodução social e cultural de vários grupos já é por eles vivida cotidianamente, e não é o CAR que desvela isso. O CAR registra o processo, por vezes, com incongruências a depender de quem mapeia. (VELCHIONE, 2016, p. 1)
\end{abstract}

Nesse sentido, se instaura um novo regime de verdade num território sobreposto que pode modificar as relações de força em um território. Evidenciar a sobreposição de terras compõe parte da "agroestratégia" (ALMEIDA, 2010) para avançar sobre territórios onde gestão ambiental e controle territorial não são sinônimos de resolução de conflitos e, muito menos, de garantia de direitos a comunidades tradicionais. (VELCHIONE, 2016)

O Novo Código Florestal, de acordo com o art. 18, dispensa averbação da Reserva Legal na matrícula do imóvel, assim, a Reserva Legal deve ser registrada apenas por meio do CAR, sem a antiga necessidade de averbação na matrícula. Por isso, o autocadastramento do CAR reduz segurança jurídica das áreas de Reserva Legal por descolar a Reserva Legal da matrícula do imóvel. Ao mesmo tempo, o Projeto de Lei do Senado (PLS) 640/2015 foi aprovado para considerar o georrefereciamento do CAR para fins de apuração de área tributável do Imposto Territorial Rural, ultrapassando sua finalidade de regularização ambiental para decretar o imposto a ser pago. Assim, inaugura o caráter fundiário, abrindo margens para quem pagar imposto sobre determinada área buscar via judicial a posse/propriedade, mesmo em terras públicas. O trabalho de Alberto di Sabatto (2008) em análise sobre a arrecadação do ITR fez interessante análise sobre a autodeclaração de informações sobre imóveis, ponderando que a informação vinda de autocadastramento, ainda que mais fácil de ser obtida, diminui a qualidade do cadastro e, por consequência, diminui a arrecadação:

Essas acentuadas diferenças indicam que pode estar havendo uma forte "manipulação" das informações por parte dos contribuintes, que estariam dessa forma evitando uma elevação do imposto que ocorreria com 
a incidência de altas alíquotas sobre os imóveis de baixo grau de utilização. Constatada a presença de "manipulação" das informações, o que se deve indagar é a razão pela qual ela é possível, já que se trata de elemento crucial do imposto, uma vez que a progressividade do ITR depende justamente de uma rigorosa apuração do grau de utilização da terra. A resposta pode ser encontrada em duas ordens de considerações, evidentemente interligadas. A primeira delas diz respeito ao fato de que a legislação do imposto, como já se viu, não estabelece parâmetros de produtividade para a área efetivamente utilizada dos imóveis rurais, exceção feita às áreas com pastagens e com atividades extrativas.

A segunda está ligada ao modo pelo qual essas informações são obtidas, já que se trata, na legislação atual, de um imposto autodeclarado. Desse modo, observando-se o preenchimento da declaração verifica-se que é bastante simples a informação sobre os dados que resultam, em particular, nas áreas efetivamente utilizadas e aproveitáveis do imóvel, a partir das quais é calculado o seu grau de utilização. Associando-se as duas ordens de considerações conclui-se que a única possibilidade de garantir a fidedignidade das informações é mediante uma ativa e abrangente fiscalização no campo, o que não parece estar ocorrendo. (SABATTO, 2008, p. 118)

Salientando a conexão das bases dos cadastros para o cálculo do ITR por meio do CAR e o caráter autodeclaratório das duas políticas, é de se esperar que a junção dos cadastros seja problemática. O ITR tem manipulações nas informações e o CAR já ultrapassou o número de imóveis passíveis de cadastros. Se na história dos cadastros, tínhamos o fólio pessoal na Lei de Terras substituído pelo fólio real através do sistema de registro imobiliário, podemos esperar da autodeclaração de território e o presente quadro de sobreposição de território como um retrocesso em matéria de domínio do território? E mais, que tipo de ações serão tomadas para corrigir esses registros sobrepostos?

Seguindo a perspectiva teórica adotada, a política autodeclaratória é um dispositivo que por sua baixa capacidade de verificação de dados e fiscalização por parte do Estado traz para os cadastros um grande número de informações que viabilizam as propriedades e posses brasileiras sem que necessariamente resolvam ou imprimam a política de regularização ambiental ou tributária de uma forma abrangente. Na realidade, a política autocadastral parece tentar capturar mais informações a sua malha, mesmo que essas informações não sejam verdadeiras e que não estejam no território. Por se tratar de um "ambiente virtual" onde os cadastros são realizados sem verificação in loco, o processo de simplificação e legibilidade do território (SCOTT, 1998) aposta confiar em todos 
os registros acionados no sistema, mesmo que com pouca verificação e fiscalização. O efeito dessa aposta é, em parte, a elucidação de milhares de sobreposições de terra que realmente existem e, em outra parte, o uso indevido da ferramenta como título fundiário e regularização ambiental de áreas em locais que não necessariamente são as do proprietário. Ao mesmo tempo, a política autocadastral possui como "efeito-instrumento" a despolitização da questão ambiental, tendo em vista que o CAR imprime autenticidade ambiental ao posseiro/proprietário, tornando-se a "identidade" da propriedade, mas a natureza do cadastro provém de uma desburocratização e flexibilização que viabiliza certificação ambiental mesmo que concebida de forma equivocada ou pouco precisa.

Portanto, os efeitos diretos da política do CAR são a expansão do número de informações ambientais para fiscalização ambiental, a política autocadastral de geração de dados altamente tecnológica e expansiva sem verificação in loco, a possibilidade de contabilizar recursos naturais e negociá-los pelas cotas de reserva ambiental, do pagamento por serviço ambiental e incentivo à política de carbono. Essas políticas combinadas com a necessidade de verificação das condições ambientais das propriedades e as denúncias de desmatamento em território brasileiro são em parte demandados pela cadeia global de commodities, que incide sobre países fornecedores de matéria-prima. O "efeito-instrumento" (FERGUSON, 1980) permite que agricultores permaneçam produzindo matérias-primas mesmo que desmatando e possuindo passivos ambientais, através de manipulações de cadastros e programas de regularização ambientais que ainda não estão em ação. Também é importante constatar alguns efeitos indiretos no território como os efeitos fundiários por sobreposição de terras públicas, onde posseiros e proprietários entregam cadastros em cima de Unidades de Conservação, terras indígenas, áreas embargadas pela União, sem nenhum tipo de responsabilização caso o cadastro seja irregular e ainda "regularizando" a situação ambiental de sua propriedade.

\section{CONCLUSÕES}

O trabalho objetivou demonstrar todo o processo de formalização de terras e de proteção ambiental brasileiro para pensar que em diferentes momentos os dispositivos acionados pelo governo acabaram se revelando ambíguos em suas intencionalidades, funcionando para amplificar as burlas já existentes, como grilagem de terras e regularização de passivos ambientais. Então, o conceito de "efeito-instrumento" de Ferguson (1980) nos ajuda a compreender 
o ferramental do novo caminho apresentado para a política pública ambiental do CAR.

Esse estudo se revela inicial a possíveis outros efeitos que possam vir a acontecer, inclusive os efeitos diretos nas áreas protegidas no Brasil, o que deverá ser feito a partir do momento em que a política pública se estabeleça de forma mais contundente e que o prazo para prorrogação do CAR, 31 de dezembro de 2019, seja cumprido e assim a política possa mostrar seus potenciais e suas carências. A constante prorrogação do prazo para realização do CAR parece aprofundar ainda mais os efeitos indiretos dessa política, alcançando objetivos exatamente contrários aos pretendidos pela política, tais como ampliação de desmatamentos e uso indevido do cadastro como documento fundiário. Por último, a atenção a políticas autocadastrais podem trazer contribuições interessantes para as análises sobre gestão de populações e biopolítica (FOUCAULT, 2008), tendo em vista que sua baixa capacidade de verificação não impede ou constrange o governo a adotar a política, mas tanto no caso do CAR quanto no ITR são incentivados. Por isso, a importância dos estudos sobre efeitos das políticas públicas, para pensar as ações estatais e as possíveis consequências de dispositivos administrativos aparentemente democráticos e benéficos que podem oportunizar efeitos dos mais diversos no território assim como revelar formas mais atualizadas de governança da terra.

\section{REFERÊNCIAS BIBLIOGRÁFICAS}

ALMEIDA, A. W. B. Agroestratégias e desterritorialização: os direitos territoriais e étnicos na mira dos estrategistas dos agronegócios. In: ALMEIDA, A. W. B. et al. Capitalismo globalizado e recursos territoriais: fronteiras da acumulação no Brasil contemporâneo. Rio de Janeiro: Lamparina, 2010. p. 101-142.

AZEVEDO, A. A. Legitimação da insustentabilidade? Análise do Sistema de Licenciamento Ambiental de Propriedades Rurais - SLAPR (Mato Grosso). 2009. 325 f. Tese (Doutorado em Desenvolvimento Sustentável) - Centro de Desenvolvimento Sustentável, Universidade de Brasília, Brasília, 2009.

CHIAVARI, J.; LOPES, C. L. Os caminhos para a regularização ambiental: decifrando o novo Código Florestal. In: SILVA, A. P. M da; MARQUES, R.; SAMBUICHI, R. H. R. (org.). Mudanças no código florestal brasileiro: desafios para a implementação da nova lei. Rio de Janeiro: Ipea, 2016. p. 21-44.

DWYER, M. B. Building the Politics Machine: Tools for "Resolving" the Global Land Grab. Development and Change, Holanda, v. 44, n. 2, p. 309-333, 2013.

FERGUSON, J. The Anti-Politics Machine: “Development”, Depoliticization, and Bureaucratic Power in Lesotho. London: University of Minnesota Press, 1980. 
FOUCAULT, M. História da Sexualidade I: a vontade de saber. Rio de Janeiro: Graal, 1985.

FOUCAULT, M. Verdade e Formas Jurídicas. Rio de Janeiro: Ed. NAU, 1997.

FOUCAULT, M. Arqueologia do Saber. São Paulo: Martins Fontes, 1998.

FOUCAULT, M. Nascimento da Biopolitica: Curso dado no College de France (1978-1979). São Paulo: Martins Fontes, 2008.

FOWERAKER, J. A luta pela terra: a economia política da fronteira pioneira no Brasil de 1930 aos dias atuais. Rio de Janeiro: Zahar, 1981.

MARTINS, P. Cadastro Ambiental Rural para a agricultura familiar: experiências e dificuldades. Curitiba: Terra de Direitos, 2016. Disponível em: http://terradedireitos. org.br/2016/06/01/cadastro-ambiental-rural-para-a-agricultura-familiar-experiencias-edificuldades/. Acesso em: 1 jun. 2016.

MCMICHAEL. P. A Food Regime Genealogy. Journal of Peasant Studies, Londres, v. 36, n. 1, p. 139-169, 2009.

MORAES, B. B. Q. Registro da propriedade imobiliária no direito brasileiro - aquisição de terras por estrangeiros. In: ALEXEEVA, T. (org.). Земля как Объект Права в России и Бразилии. São Petersburgo: HSE, 2014.

MOREIRA, E. O cadastro ambiental rural: a nova face da grilagem na Amazônia? Disponível em: http://www.abrampa.org.br/site/?ct=noticia\&id=230. Acesso em: 24/04/2017.

NEVES, E. F. Posseiros, rendeiros e proprietários: estrutura fundiária e dinâmica agromercantil no Alto Sertão da Bahia (1750-1850). 2003. $423 \mathrm{f}$. Tese (Doutorado em História) - Programa de Pós-Graduação em História, Universidade Federal de Pernambuco, Recife, 2003.

PORTO, J. R. S. Poder e território no Baixo Sul da Bahia: os discursos e os arranjos políticos de desenvolvimento. 2016. 308 f. Tese (Doutorado em Ciências Sociais) - Programa de Pós-Graduação de Ciências Sociais em Desenvolvimento Agricultura, Universidade Federal Rural do Rio de Janeiro, Rio de Janeiro, 2016.

SABBATO, A. A intervenção no mercado de terras rurais no Brasil: um estudo sobre o crédito fundiário e o imposto territorial rural no período 1997-2002. 2008. 148 f. Tese (Doutorado em Ciências Sociais) - Programa de Pós-Graduação de Ciências Sociais em Desenvolvimento Agricultura, Universidade Federal Rural do Rio de Janeiro, 2008.

SCOTT, J. C. Seeing Like a State: How Certain Schemes to Improve the Human Condition Have Failed. Yale University Press, Londres, 1998.

SHORE, C. WRIGHT, S. Anthropology of Policy: Critical Perspectives on Governance and Power. London: Routledge, 1997.

SILVA, L. O. Terras devolutas e latifúndio: efeitos da lei de 1850. Campinas: Ed. Unicamp, 1996. 
SOARES FILHO, B.; RAJÃO, R.; MACEDO, M.; CARNEIRO, A.; COSTA, W.; COE, M.; RODRIGUES, H.; ALENCAR, A. Cracking Brazil's Forest Code. Science, Washington D.C., v. 344, p. 363-364, 2014.

THE NATURE CONSERVANCY. Cadastro Ambiental Rural (CAR): nasce a identidade do imóvel rural. Curitiba: TNC, 2015. Disponível em: https://www.nature.org/media/ brasil/cadastro-ambiental-rural.pdf. Acesso em: 1 ago. 2017.

TRECANNI, G. Violência e Grilagem: instrumentos de aquisição de propriedade da terra no Pará. Belém: UFPA, 2001.

VELCHIONE, M. Cadastro Ambiental Rural (CAR) e a secundarização de reformas fundamentais para a garantia da posse da terra. Terra de Direitos, 14 jun. 2016. Disponível em: https://terradedireitos.org.br/acervo/artigos/artigo-cadastroambiental-rural-car-e-a-secundarizacao-de-reformas-fundamentais-para-agarantia-da-posse-da-terra/22476. Acesso em: 5 set. 2017. 